\title{
Lateral Hypothalamic Control of Metabolic Factors Related to Feeding
}

\author{
S. Nicolaidis \\ Laboratoire de Neurobiologie des Régulations C.N.R.S., Collège de France, Paris, France
}

Summary. States of hunger and satiety are under ischymetric (i. e., rate of cellular energy production) control which depends on both substrate availability and hormonal composition. The latter varies in response to external (olfactory, gustatory and gastrointestinal) stimuli sensed by specific receptors and projected on lateral hypothalamic $(\mathrm{LH})$ units from which departs the descendant control pathway of metabolic glands. This neurohormonal loop is responsible for the anticipatory glycemic and other changes observed during a meal and the preabsorptive "satiation" ending the meal long before the postabsorptive cellular repletion will induce the state of more permanent "satiety". New data on LH "sweet" taste projection and hypothalamo-pancreatic control are shown and strengthen the above view.

Key words: Oro-glycemic reflex, hypothalamic taste units, preabsorptive satiation, insulin, glucagon, metabolism.

\section{Ischymetric Dependence of Hunger and Satiety}

Although homeorheusis ${ }^{1}$ of glycemia is achieved through continuous utilization of endogenous reserves, the ultimate source of replenishment is located in the environment and has to be behaviorally acquired. In fact, numerous observations of feeding in animals [25], and reports of hunger [28] in humans in relation to severe hypoglycemia led to the concept of a glucostatic mechanism of feeding and to its immensely seminal description as the glucostatic theory by Jean Mayer [23, 24]. The subsequent failure to explain persistent feeding in spite of large

\footnotetext{
1 Homeorheusis: the dynamic version of homeostasis, where rheusis (in Greek: flow) replaces stasis (in Greek: stagnation). It designates the maintenance of a value at a level which may vary, but only according to a biologically determined program, such as circadian or annual rhythms
}

intravenous (iv) loads of glucose $[1,2,20,51]$, together with the same reasoning for lipids and amino acids, led to other sorts of "molecular static" theories (for rev. see [59]). All of them were justified by some reasonably good experimental evidence. Today, this partial validation of all of the previous hypotheses is explained by the ischymetric (ischys: power or rate of energy production) hypothesis [34, 38 ] which proposes that the ultimate stimulus of the specific arousal of hunger is the drop below a critical level of power production in specific diencephalic cells sharing the general metabolism of the body.

The hypothalamus can be considered from the metabolic point of view as a microcosm of the somatic macrocosm. Hypothalamic units are constantly informed of the repletion/depletion state of the inner milieu (for rev. see [44]) and, at the same time, of recent ingestants $[31,32]$. Taking into account the actual situation of energogenic reserves (adipose and other) and potential repletion (ingestants), hypothalamic units produce their own metabolic hormones $[14,58]$ and modulate the release of metabolic hormones from peripheral glands. The hypothalamus receives much more information than the plasma-concentration-oriented pancreatic endocrine cells. Following a well-adapted integration of all of them, the hypothalamus projects the final common order to the islet endocrine cells. In this integrative universe, we begin understanding a part of the early metabolic changes occurring at the preabsorptive phase of feeding and its potential role on feeding itșelf. The old unresolved problem of the early, preabsorptive satiation ${ }^{2}$ seems to be due to a new metabolic situation of repletion induced in advance

\footnotetext{
${ }^{2}$ Satiation is the state which terminates an ad libitum meal or drinking. It is characterized by the (pre-absorptive) disappearance of hunger or of thirst as opposed to the more permanent state of satiety of no hunger or no thirst which progressively replaces satiation during the interval between two successive ingestive events. In common language, satiation of water would correspond to "quenching" though "fullness" would express satiation for food
} 


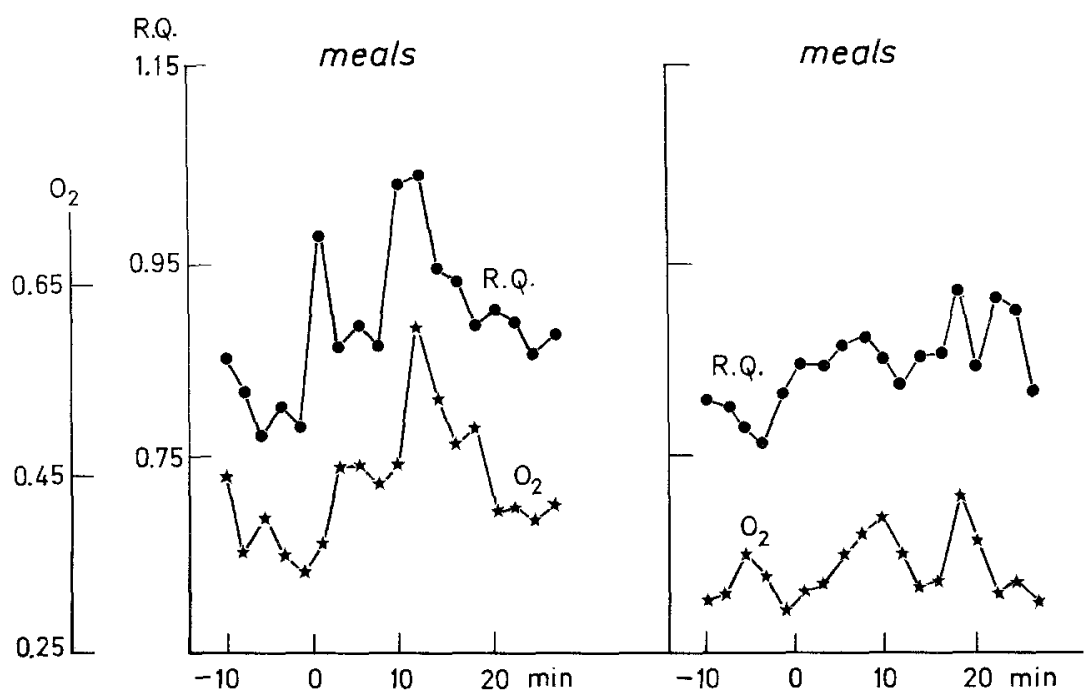

Fig. 1. On the left: mean $\mathrm{O}_{2}$ consumption and R. Q. before, during and after spontaneous meals. The decrease of metabolic rate and glycolysis coincided with the onset of meals. Both $\mathrm{O}_{2}$ consumption and $\mathrm{R}$. $\mathrm{Q}$. were higher after than before the onset of the meal. On the right: propranolol $(1 \mathrm{mg} / \mathrm{kg})$ blocked these responses to the intestinal absorption by endocrine adaptations triggered by oro-sensory anticipatory reflexes $[32$, 37] via hypothalamic centers.

We shall consider some of these early metabolic adaptations as well as the afferent pathways, their projection to specific integrative cells and their efferent route to peripheral glands dealing with these early metabolic adaptations.

\section{Metabolic Fluctuations and Feeding}

\section{a) Gas Exchange and Feeding}

The hypometabolic state of hungry animals and humans as opposed to a hypermetabolic one during satiety was recognized since the beginning of measurements of metabolism [3]. The low level of $\mathrm{O}_{2}$ consumption and of respiratory quotient (R. Q.; i. e., respiratory signature of breakdown of fat reserves) of starved animals is replaced, after feeding, by a new, higher level of $\mathrm{O}_{2}$ consumption and R.Q. (indicating the utilization of a majority of carbohydrate substrates). More recently, it was shown that this switch from the metabolic state $\left(\mathrm{O}_{2}\right.$ and R. Q.) characteristic of hunger to that of satiety does not wait for the intestinal absorption of the ingestants to occur. The rise of R. Q. and of backround metabolism is reflexly triggered by oro-digestive afferent signals announcing nutritive repletion before the nutrient's intestinal absorption (Fig. 1). Equivalent metabolic $\left(\mathrm{O}_{2}\right.$ and R. Q.) adaptations are observed in tube fed rats. They are triggered by cues originated by the arrival of nutrients in the stomach in the absence of any movement of the rat [31]. In the rat, this anticipatory metabolic adaptation coincides with the end of the meal; i. e., with its pre-absorptive satiation [31, 32]. In other words, the metabolic rate tends to decrease when animals are depleted and hungry and it returns to higher levels as soon as the deficit is potentially covered by feeding.

According to the ischymetric view, hunger is precisely due to the lowered metabolic rate; its aggravation precipitates the onset of a meal (Fig. 1) and its restoration causes permanent satiety. As far as the pre-absorptive satiation is concerned, it could also be due to the early pre-absorptive restoration of the metabolic rate. This early reversal of metabolism is made at the expense of rapidly and reflexively liberated metabolites from endogenous reserves. The concomitant increase in both $\mathrm{O}_{2}$ consumption and R. Q. show that the main endogenous substrate so mobilized is carbohydrate [30].

\section{b) Glycemia and Feeding}

The first unequivocal oro-glycemic reflex was shown in the rat by means of a continuous aspiration through an iv cannula and a continuous in vivo assay using an auto-analyzer (Technicon) (Fig. 2) [29, 32]. Oral stimulations with sucrose or saccharine solutions trigger an almost immediate hyperglycemic response (Fig. 2), sometimes preceded by an short hypoglycemia. The hyperglycemic response is more dramatic in previously deprived rats, than in those fed ad libitum. The specificity and the reflex nature of such responses are well recognized today $[54,55]$. The respective role of the oral vs gastro-intestinal receptors and the influence of sham feeding have been investigated in chronically implanted freely moving and eating animals.

\section{c) Pancreatic Hormones and Feeding}

It was also shown that the early glycemic adaptations are due to a dramatic, almost immediate, release of 


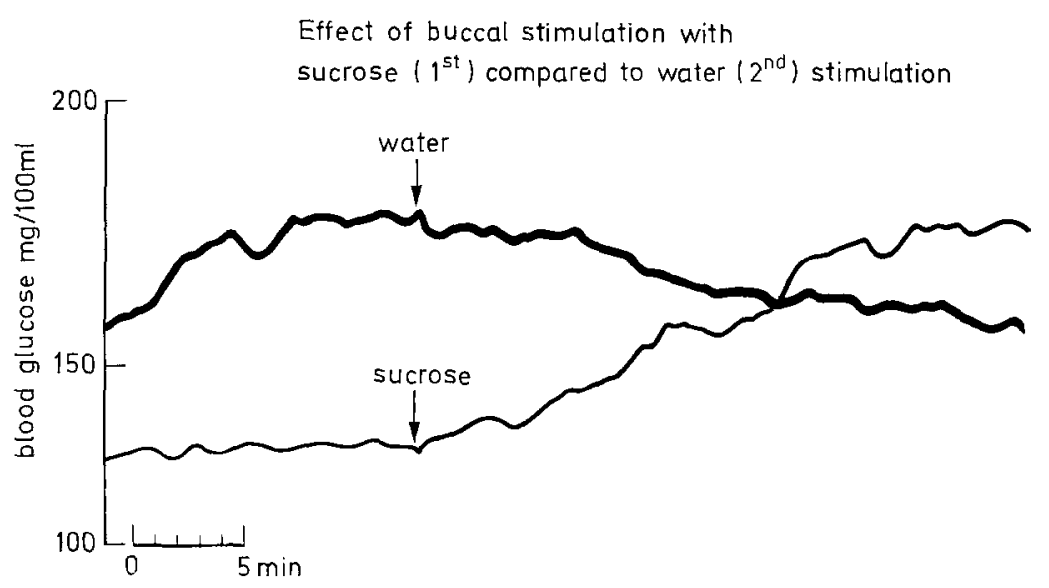

Fig. 2. An individual in vivo continuous iv sampling and glucose assay by an autoanalyzer (the upper trace is a continuation of the bottom one). Oral stimulation with $30 \%$ sucrose $(3-5 \mathrm{ml})$, indicated by the arrows triggered the hyperglycemic reflex although control stimulation did not (from Nicolaidis [32]) glucagon followed by a release of insulin [55, 57]. Although several hormonal factors may participate in the feeding-associated metabolic changes, the combined action of these two metabolic hormones can, by itself, explain the overall metabolic phenomena occurring at the onset of a meal. On one hand, the rapid hyperglycemic response can be accounted for by the early glucagon discharge and on the other, the rise of metabolic rate together with the R. Q. (meaning that the new metabolism uses carbohydrates predominantly) can be due to the insulin discharge. We shall restrict our study to this particular aspect of the variety of oro-visceral reflexes.

\section{Sensory-Pancreatic Reflex Loop - Pathways and Centers}

\section{a) Peripheral Receptors and Ascending Pathways}

Oral receptors and afferent pathways have been extensively investigated. Specific sweet-taste lingual receptors project distinctly to the nucleus fasciculus solitarius, from which they ascend toward the forebrain following two separate pathways. Discriminatory vagal afferents from the gastrointestinal wall have also been described [26], like the upper intestinal chemo-sensitive information they project into the nucleus fasciculus solitarius. As far as the two ascending pathways are concerned, one is the classical lemniscal bundle ending in thalamic relays from which originate the thalamo-cortical projections leading to conscious perception of sweetness. We shall deal with the second ascending pathway ending within hypothalamic and limbic structures from which originate visceral nerves of non-conscious autonomic controls. The progression of the pathway from the nucleus fasciculus to the hypothalamolimbic system was carefully investigated by Norgren [40]. He described a (at least partial) first projection of gustatory fibers in the tegmental area with relay in the pontine area which also receives direct glosso- pharyngeal afferents. Besides the hypothalamic projections, there are also ipsi- and contralateral thalamic ones. The hypothalamic projections are bilateral and lie essentially in an area extending from the descending fornical column to the internal capsule laterally and the bed nucleus of the stria terminalis from which the gustatory information can reach the amygdaloid complex. These sites are in quite good agreement with those projections described previously and subsequently. Since our first report of gustatory projections in lateral hypothalamic areas [31, 32], this non-orthodox type of sensory projection has been widely confirmed, not only for gustatory $[40,41]$ but also for olfactory [52] and some more-complex visual motivation-bound stimulations $[50,60]$. Although our first investigations dealt mainly with non-sweet gustatory modalities, it is now established that the LH area is the site of projection of lingual sweet stimulations which are independent of motivational determinants, since, as we show below, they were found in anesthetized preparations.

\section{b) Specific Non-motivation-bound Lateral Hypothalamic Projections of Lingual Sweet Stimulations}

\section{Materials and Methods}

Fourteen, 24-hour food-deprived rats anesthetized with chloralose were used in these experiments. After oesophageal ligature, their mouth was kept open by forcing the jaw downwards. A new apparatus for specific gustatory stimulation was used in these experiments. Two cannulae were introduced at the level of the declivitous lingual $\mathrm{V}$ without touching it. One was filled with a $20 \%$ glucose solution and the other one contained a control solution of $20 \%$ mannitol. Both cannulae were surrounded by an independent tubing through which water at $34^{\circ} \mathrm{C}$ was continuously applied. Previous measurements had shown that under these conditions, the stimulating fluids were kept at $33.4 \pm 0.6$ degrees from the very first drops to the end of the $2 \mathrm{ml}$ fluid flowing out for a period of 10 seconds.

Recording of single hypothalamic units was made by stainless steel concentric electrodes. Their tip diameter was electrolytically sharpened to 1.5 to $2 \mu$ and their impedance approximated 1 


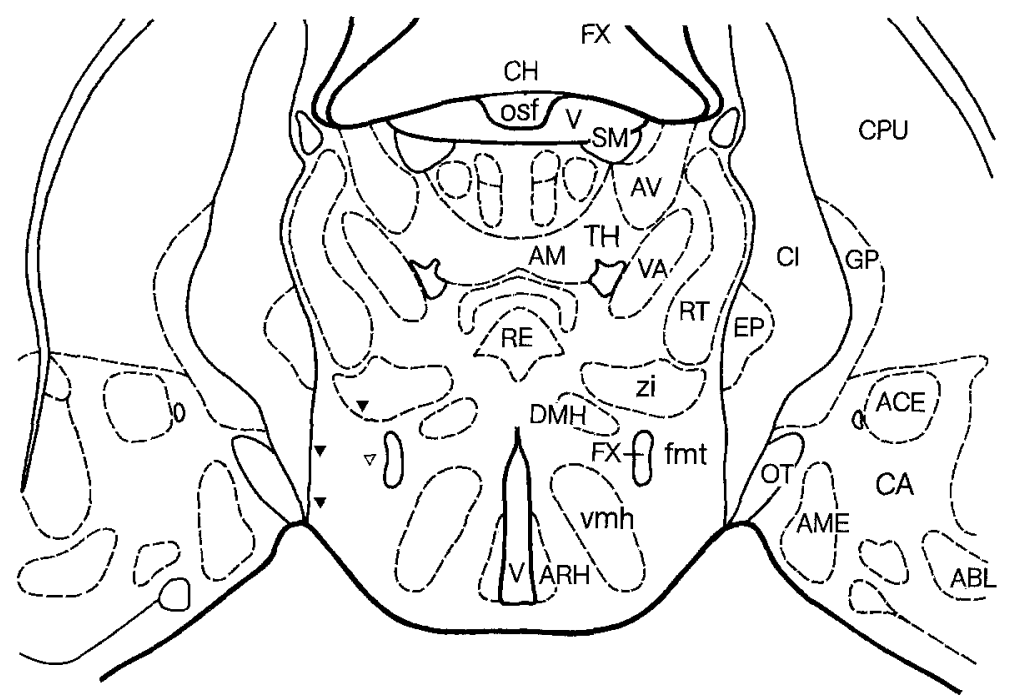

Fig. 3. Location of units responding to glucose stimulation of the tongue but not to mannitol nor to the other arousing stimuli megaohm. The pauci-unit activity was selected by using electronic gates in order to retain on single unit to be tested for its response to glucose stimulation of the tongue, provided that the response was specific; i. e., if a similar response was also found after a control mannitol application, the unit was discarded. All of the investigated units were previously tested with non-specific arousal stimuli such as noise or skin pinching. Those units responding to nonspecific stimuli were not studied for their taste responsiveness. The anatomical location was obtained by using the Prussian blue technique after electrolytic marking of the recording tip.

\section{Results}

Among the 106 noise and skin pinching-indifferent units, only four were responsive to glucose solution but not to mannitol. Three of these units were inhibited and one showed a clear acceleration. The last unit was located in the external parafornical area (Fig. 3), though the units whose basal activity was decreased were scattered more externally; one was in the lower limit of zona incerta and the two others within the most external part of the medial forebrain bundle (Fig. 3). The latency of response was difficult to measure with satisfactory precision because the precise instant of sensory impact by the solution is difficult to assess. It seems that all of the latencies were longer than $80 \mathrm{msec}$ and less than $175 \mathrm{msec}$. The response was persistent for as long as 1.3 to 4.5 minutes. The unit which showed an excitatory response to the sweet taste was also sensitive to the ambient brightness. Switching off the lights was a potent stimulus evoking a type of "slow adapting" activity. When darkness and glucose were applied simultaneously, the response was similar to that of switching off the lights.

\section{c) Hypothalamic Integrative Units}

The lateral hypothalamic area is scattered with units which possess integrative properties. The same units firing specifically to chemicals injected in the internal carotid artery respond also, in a similar way, to the same chemicals applied on the tongue [31,32]. Since this first description, other interoceptive and exteroceptive convergences were found, making this area a powerful integrative "device" for a variety of information known to play a modulatory role on glycemia. In particular, Rolls and his co-workers [49], using conscious monkeys, have shown that in this same $\mathrm{LH}$ area extended to the substantia innominata, $13 \%$ of the activity of the neurons was related to feeding. The activity of $2 \%$ of them was altered only during the ingestion of glucose containing fluids. The majority of these neurons respond to the sight of the nutritive substance, though they do not respond while the monkey is looking at non-food objects. An important property of these units is that they do not respond to either of the above visual or taste stimuli when the animals are satiated. In other words, the responsiveness of these taste-sensitive units varies according to the animal's motivation. The motivational prerequisite of the monkey taste-sensitive units is confirmed by observations of their activation by convergent information of reward originated by both natural stimuli and brain-stimulations [50]. This observation does not apply to sweet taste hypothalamic projection found in chloralose-anesthetized rats. As we mentioned above, the degree of the orally elicited hyperglycemic response was found to be dependent on the duration of starvation preceding the experiment [32]. Despite the fact that rats were anesthetized in these experiments, the fact that all of the peripheral inputs converging in LH glucosensitive cells show long latencies indicate that the underlying pathways could not be exactly the bi-synaptic ones described by Norgren [41], nor the thalamus-mediated ones reported by Emmers [8]. Rather, they seem to be the end of a polysynaptic system superimposing many individual distorsions to the objective information arriving from the periphery. The motiva- 
tion dependent modulation of taste afferents favors this view. In addition, recent data from the Fukuoka School $[45,46]$ show that both VMH and LH areas receive excitatory and inhibitory synaptic inputs from the limbic system, the pyramidal and extrapyramidal motor systems, the frontal association area and, of course, the suprachiasmatic nucleus. If we add to these projections those from the stomach (distension and sensory specific) and intestine [48] and the possibility that gastrointestinal hormones (CCK-PZ, GIP, gastrin, etc) can influence islet secretion directly or through hypothalamic action [19], one can get a better (not simpler ...) idea of the complexity of hypothalamic integration. However, the multisensory and conditioning-bound influence [62] should not minimize the underlying basal integration of the blood-borne metabolic information. As Oomura and his co-workers have shown, not only are lateral hypothalamic units glucosensitive [43], but they also take into account the chemical composition of their extracellular environment in the sense that their glucosensitivity decreases when FFA concentration increases. If we add to this the Randle-type antagonistic metabolic action of the two main chemical families of nutrients, the recently shown insulin production $[14,58]$ and the local production of perhaps all of the metabolically active peptides such as somatostatin [4], the hypothalamus tends to appear as the best microcosmic metabolic image of the whole body macrocosm. This is the working hypothesis that we shall consider next, before studying the efferent command, finally generated in the $\mathrm{LH}$, and directed toward the pancreatic islets.

\section{d) The Effect of False Lipogenic Information Applied Directly in the Hypothalamus}

The working hypothesis in this investigation was derived from the above conclusion and dealt with the way the level of body weight is signalled to the hypothalamus and elicits corrective responses. Long term body energy regulation is achieved because those central structures which control metabolic and ingestive responses continuously take into account the actual total body lipid stores. It has been generally asserted that the peripheral message to the brain is necessarily some circulating factor(s) proportional to the amount of the somatic fat storage. We have proposed an alternative mechanism continuously able to inform the brain of the state of peripheral stores; i. e. the possibility that some neural elements (neuroglial complexes) possess, at the level of their excitable membrane, an enzymatic equipment similar to that of peripheral adipocytes [35]. As a result, excitability of the centers should decrease when lipogenesis increases, thus becoming a central index (microcosm) proportional to the peripheral fat con- tent (macrocosm) without the contribution of any centripetal signal. The feasibility of such a mechanism was confirmed by measurement of hypothalamic fragments of obese rats. These were found to contain more lipids than the hypothalamic fragments of control animals and more than those of lean rats. This difference was not found in fragments of cerebellum [35]. Accordingly, an experimental alteration of the local hypothalamic adiposity should be able to fool the "regulator" and to generate a negative feed-back displacement of the peripheral adiposity. Rats with bilaterally implanted cannulae at the level of the descending fornical column were continuously infused with a $0.005 \mathrm{IU} / \mu \mathrm{l}$ insulin solution $(1.5 \mu \mathrm{l} / \mathrm{h})$ while control rats received the solvent. Rats whose hypothalamus was thus exposed to the lipogenetic hormone insulin for 3 to 7 days became hypophagic until they reached a lower body weight which thereafter was defended for as long as three months. Figure 4 shows a typical example of a pair of littermates of equal initial weight. After bilateral cannula implantation and post-operative recovery, they were continuously infused with the insulin solution for seven consecutive days. Infusion of the vehicle did not significantly modify food intake and, as far as body weight was concerned, short-term and longterm gain was normal. On the contrary, intrahypothalamic insulin brought about a rapid decrease in both food intake and body weight. Most remarkable was the long-lasting effect on body weight regulation, which was achieved around a lower level. Notice, however, that near the end of the period of observation (8th week) a slight tendency to approach the control level of body weight was obvious. This longdelayed tendency is typical and suggests that some additional compensatory mechanism does exist and has to be investigated. These data confirm our preliminary report [36] on rats and similar elegant data on intraventricular insulin infusion on baboons recently published by Woods et al. [63].

\section{e) LH Control of Glucagon and Insulin Secretion and Efferent Pathways}

There are many ways the hypothalamus can act upon pancreatic islet secretion. One of its modulatory actions can utilize a hormonal route since growth hormone, somatostatin, thyroxin, cortisol, estrogens and androgens, in addition to the hypothetical insulin releasing substance [18], regulate the tone of islet responsiveness. In this paper we do not deal with such mechanisms nor do we consider the role of local catecholamines which is reviewed by Steffens elsewhere in this volume. Rather we shall report our recent findings on the role of the LH area on glucagon and insulin secretion and on the neural efferent pathway of this control. 


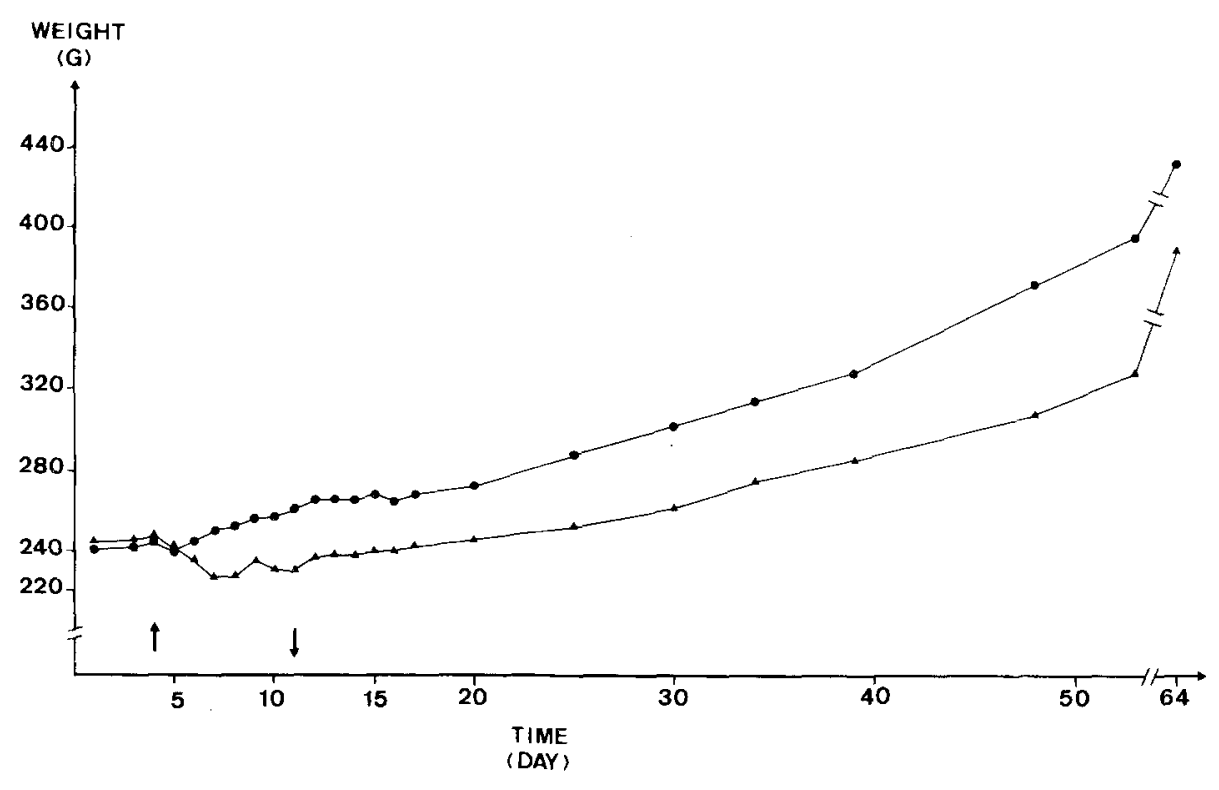

Fig. 4. Short and long term effect on body weight of two littermate rats receiving a 7-day intra hypothalamic infusion of a solution of insulin (triangles) or vehicle (circles)
Contrary to the generally suggested role of the VMH to inhibit insulin secretion $[10,17,56,65$, for a review see 64] and enhance glucagon secretion, the action of the lateral hypothalamus on these two hormones is controversial. The usual conception of the dual-center functioning of feeding behavior and related functions predicted that the $\mathrm{LH}$ (a parasympathetic center) would be antagonistic to the VMH (a sympathetic center) area enhancing insulin and inhibiting glucagon secretion. This effect was reportedly shown by early investigations. Bilateral destruction of VLH was reported to result in a decrease of plasma insulin in rats [56] and genetically obese mice, with no change in normal mice [6]. Electrical stimulation of the VLH reportedly caused hypoglycemia [12, $21,53]$ with its logical hormonal effects of increased plasma insulin $[18,22,56]$. However, other investigators did not find changes in fasting insulin level [11]. In another report, VLH stimulation resulted in an increase in blood glucose [5] and in glucose and glucagon levels without substantial change of insulin level [47]. The contradiction of previous data, the methodological problems of constant voltage stimulations whose characteristics were incompatible with circumscribed activation, and the absence of appropriate controls or histological analysis, led us to consider the VLH action on islet secretion as a question still open to discussion and to undertake a series of new experiments $[15,16]$.

Thiopenthal-anesthetized, enterectomized (in order to exclude enteroglucagon) fed-ad-libitum rats were used in these experiments. They were first bilaterally implanted with 2 bipolar electrodes cemented to the skull and then removed from the stereotaxic instrument which, in preliminary experiments, was shown to alter pancreatic hormones and glycemia by

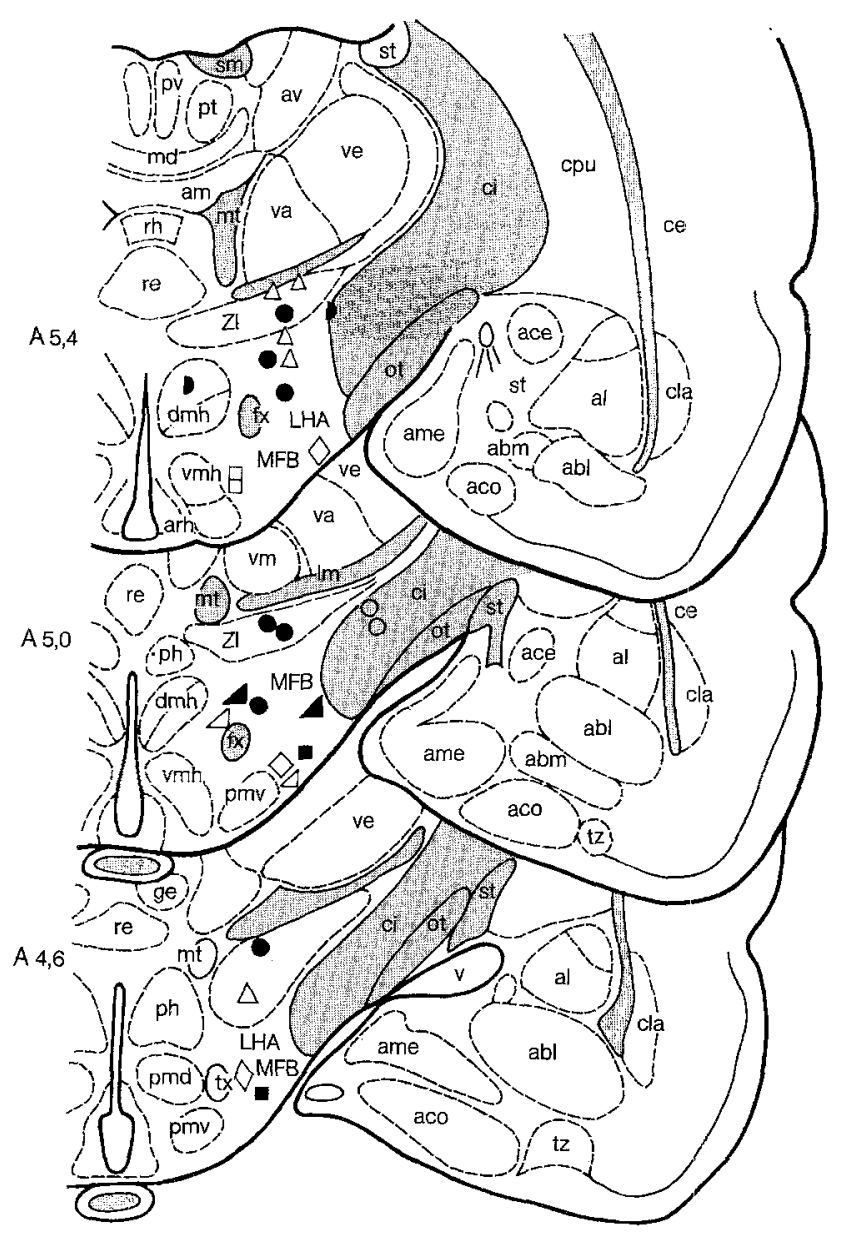

Fig. 5. Sites of stimulation of intact or vagotomized or sympathectomized animals. Filled marks elicit glucagon secretion from the pancreas, empty do not 
the stress of its attachment. The abdominal operation consisted of catheterization of the portal vein with the catheter tip placed just below the pancreatic vein, and in neural sections or adrenalectomy whenever it was necessary. The electric stimulations were delivered through two insulation units equipped with a constant current device regulated to maintain $6 \mu \mathrm{A}$ with $50 \mathrm{~Hz}, 2 \mathrm{~ms}$ impulses. The rat was allowed to recover from surgery, thermoregulated and kept under a $95 \% \mathrm{O}_{2}+5 \% \mathrm{CO}_{2}$ atmosphere. Control rats were submitted to an identical schedule except that the stimulating cables were not connected to the stimulator. In addition, extra-LH implantations were performed to test the effect of identical extrahypothalamic stimulations. All animal tissues were fixed in formalin in vivo and careful histological investigation was made in order to map the stimulating electrode tips.

In the first series of experiments, the stimulation site was aimed at the LH area in which electrophysiological recordings had shown units responding to lingual sweet stimulations (compare sweet taste projecting sites to those eliciting glucagon release and insulin hyporesponsiveness in Figure 5).

The main findings of these experiments show that the $\mathrm{LH}$ area, from the descending fornical column to the internal capsula and up to zona incerta, is the site from which stimulations elicit an increase in portal plasma IRG. The portal IRI level was kept low in spite of the unequivocal rise of blood glucose level. This control was transmitted mainly by splanchnic nerves whose section favored an increase in plasma IRI. Vagotomy had an opposite effect on IRI which decreased when LH was stimulated bringing about hyperglycemia and persistence of IRG discharge.

\section{Metabolic Endocrine Responses as the Final Common Pathway of a Cascade of Integrations}

The activity of the endocrine pancreatic cells takes into account the plasma composition of the metabolites themselves and, in addition, other humoral and nervous messages. All of these three controllers of the islet cell can be influenced by various hypothalamic mechanisms. This is true for the plasma substrate composition which can be modified through other endocrine and perhaps direct nervous routes. But, this is more subtle through hormonal or neuromodulatory factors known to influence the tone of secretory responsiveness of the islet cells. This paper dealt with the third type of hypothalamic control of metabolism acting upon peripheral glands, among which the pancreas occupies a prominent position. Nervous modulation of glucagon and insulin release was shown to be very powerful. Such rapid and dramatic mobilizations of metabolic hormones and mobilization and storage of metabolites is often met not only in various irregular circumstances such as effort or stress, but also in a very regular one, feeding. In feeding the subtle and powerful central modulation of pancreatic secretions elicits anticipatory and optimizing responses and smoothes the metabolic stress of ingestion $[32,37]$. In fact, it seems to do much more, since the central modulation of metabolism may be sensed by ischymetric receptors determining in turn the degree of hunger and satiety and that of the transient satiation on which depends the size of a meal. This double feed-back influence seems to be responsible for the harmony between metabolic needs and behaviors like feeding and sleep [7] dealing with the renewal, storage and utilization of energogenic substrates.

\section{References}

1. Adair ER, Miller NE, Booth D (1968) Effects of continuous intravenous infusion of nutritive substances on consumatory behavior in rats. Commun Behav Biol 2: 25-37

2. Baile CA, Zinn W, Mayer J (1971) Feeding behavior of monkeys: glucose utilization and site of glucose entry. Physiol Behav 6: 537-542

3. Benedict FG, Miles WR, Roth P, Smith M (1919) Human vitality and efficiency under prolonged restricted diet. Carnegie Institution of Washington 280: p 701

4. Brazeau P, Wale W, Burgus R, Ling W, Butcher M, Rivier J Guillemin R (1973) Hypothalamic polypeptide that inhibits the secretion of immunoreactive pituitary growth hormone. Science 179: 77-79

5. Booth DA, Miller NE (1969) Lateral hypothalamus mediated effects of a food signal on blood glucose concentration. Physiol Behav 4: 1003-1009

6. Chlouverakis C, Bernardis LL (1972) Ventrolateral hypothalamic lesions in obese hyperglycemic mice (obob). Diabetologia 8: 179-184

7. Danguir J, Nicolaidis S (1980) Intravenous infusion of nutrients and sleep in the rat: an ischymetric sleep regulation hypothesis. Am J Physiol 228: E, 307-E. 312

8. Emmers R (1973) Interaction of neural systems which control body water. Brain Res 49: 323-348

9. Fennegan FM, Puiggari MJ (1966) Hypothalamic and amygdaloid influence on gastric motility in dogs. J Neurosurg 24: 497-504

10. Frohman LA, Bernardis LL (1968) Growth hormone and insulin levels in weanling rats with ventromedial hypothalamic lesions. Endocrinology 82: 1125-1132

11. Frohman LA, Bernardis LL (1971) Effect of hypothalamic stimulation on plasma glucose, insulin and glucagon levels. Am J Physiol 221: 1596-1603

12. Gellhorn, E, Cortell R, Feldman J (1941) The effect of emotion, sham rage and hypothalamic stimulation on the vagoinsulin system. Am J Physiol 133: 532-541

13. Glavcheva L, Manchanda SK, Box B, Stevenson JAF (1972) Gastric motor activity during feeding induced by stimulation of the lateral hypothalamus in the rat. Can J Physiol Pharmacol 50: 1091-1098

14. Havrankova J, Schmechel D, Roth J, Browstein M (1978) Identification of insulin in rat brain. Proc Natl Acad Sci USA 55: 5737-5741

15. Helman A, Amira R, Assan R, Nicolaidis S (1978) Hypo- 
thalamic ventro-lateral (VLH) stimulation induces glucagon release in the rat. Diabetologia 15: 238

16. Helman A, Amira R, Nicolaidis S, Assan R (1980) Glucagon release by lateral hypothalamic stimulation and its efferent pathway in the rat. Endocrinology 106: 1612-1619

17. Hustvedt BE, Lovo A (1972) Correlation between hyperinsulinemia and hyperphagia in rats with ventromedial lesions. Acta Physiol Scand 84: 29-33

18. Idahl LA, Martin JM (1971) Stimulation of insulin release by a ventro-lateral hypothalamic factor. J Endocrinol 51: 601-602

19. Ishibashi S, Oomura Y, Okajima T (1979) Facilitatory and inhibitory effect of TRH on the lateral hypothalamic and ventromedial neurons. Physiol Behav 22: 785-787

20. Janowitz HD, Grossman MI, (1948) Some factors affecting the food intake of normal dogs and dogs with oesophagotomy and gastric fistula. Am J Physiol 159: 143-148

21. Kurotsu T, Tabayashi C, Ban T (1953) Influence of the endocrine organs upon changes of blood sugar induced by the electrical stimulation of the hypothalamic nucleus. Med J Osaka Univ 3: 529-546

22. Kuzuya $T$ (1962) Regulation of insulin secretion by the central nervous system - II. The role of the hypothalamus and the pituitary gland upon insulin secretion. Nippon Noika Gakkai Zasshi 51: 65-74

23. Mayer J (1952) The glucostatic theory of regulation of food intake and the problem of obesity. Bull NE Med Cen 14: $43-49$

24. Mayer J (1955) Regulation of energy intake and body weight. The glucostatic theory and the lipostatic hypothesis Ann NY Acad Sci 63: 15-43

25. McKay EM, Callaway JW, Barnes RH (1940) Hyperalimentation in normal animals produced by protamine insulin. J Nutr 20: $59-66$

26. Mei $N(1978)$ Vagal glucoreceptors in the small intestine of the cat. J Physiol (Lond) 282: 485-506

27. Misher A, Brooks FP (1964) Augmented interdigestive gastric secretion during electrical stimulation of the lateral hypothalamus. Physiologist 7: 207

28. Morgan CT, Morgan JO (1940) Genet Psychol 57: 153

29. Nicolaidis S, Le Magnen $\mathbf{J}$ (1966) Etude de l'action des stimulations buccales sur la glycémie. Proceedings du Symposium Technicon, Paris, p 3

30. Nicolaidis S, Le Magnen J, Portet R (1966) Modification réflexe du quotient respiratoire chez le rat sous l'effet de stimulations alimentaires périphériques. J Physiol (Paris) 58: 576

31. Nicolaidis S (1968) The prandial calorigenic effect. 3rd Int. Conference on Food and Water Intake, Haverford Penn

32. Nicolaidis S (1969) Early systemic responses to oro-gastric stimulation in the regulation of food and water balance. Functional and electrophysiological data. Ann NY Acad Sci 157: $1176-1203$

33. Nicolaidis S (1969) Discriminatory responses of hypothalamic osmosensitive units to gustatory stimulation in cats. Olfaction \& Taste, III., New York, p 569-573

34. Nicolaidis S (1974) Short-term and long-term regulation of energy balance. XXVI Int. Congress of Physiological Sciences. Proceedings of the International Union of Physiological Sciences, vol X. New Delhi, p 122-123

35. Nicolaidis S, Petit M, Polonowski J (1975) Etude du rapport entre la régulation de la masse adipeuse corporelle et la composition lipidique de ses "centres régulateurs". C R Acad Sci (Paris) 278: 1393-1396

36. Nicolaidis S (1978) Mécanisme nerveux de l'équilibre énergétique. In: J Ann Diabet Hôtel Dieu, Flammarion Paris, 153-156

37. Nicolaidis S (1978) Rôle des réflexes anticipateurs orovégétatifs dans la régulation hydrominérale et énergétique. J Physiol (Paris) 74: 1-19
38. Nicolaidis S, Rowland, N (1976) Metering of intravenous versus oral nutrients and regulation of energy balance. Am J Physiol 231: 661-669

39. Niijima A (1979) Control of liver function and neuroendocrine regulation of blood glucose levels. In Brooks CMC, Koizumi K, Sato A (eds) Integrative function of the autonomic nervous system. Univ. Tokyo Press, Tokyo

40. Norgren R (1976) Taste pathways to hypothalamus and amygdala. J Comp Neurol 166: 17-30

41. Norgren R, Leonard CM (1971) Taste pathways in rat brainstem. Sciences 173: 1136-1139

42. Novin D (1962) The relation between electrical conductivity of brain tissue and thirst in the rat. J Comp Physiol Psychol 55: $145-154$

43. Oomura Y, Ono T, Ooyama H, Wayner MJ (1969) Glucose and osmosensitive neurons of the rat hypothalamus. Nature 222: $282-284$

44. Oomura Y (1976) Significance of glucose, insulin and free fatty acids on the hypothalamic feeding and satiety neurons. In: Novin D, Wyrwicka W, Bray G (eds) Hunger: basic mechanisms and clinical implications, Raven Press, New York, p 65-142

45. Oomura Y, Ohta M, Kita H, Ishibashi S, Okajima T, Nicolaidis S (1977) Effect of derivatives on glucoreceptor neurons in the rat ventromedial hypothalamic nucleus. Proc Physiol Soc Japan

46. Oomura $Y$, Ono $T$, Nishino $H$, Kita $H$, Shimizu N, Ishizuka S, Sasaki K (1979) Hypothalamic control of feeding behavior: modulation by the suprachiasmatic nucleus. In: Suda M, Hayaishi $O$, Nakagawa $H$ (eds). Biological rhythms and their central mechanism. Elsevier Press, Amsterdam Oxford New York, p 285-307

47. Parameswaran SV, Steffens AB, Hervey GR, de Pimster L (1977) Involvement of a humoral factor in regulation of body weight in parabiotic rats. Am J Physiol 245: R150R157

48. Rogers RC, Novin D, Butcher LL (1979) Electrophysiological and neuroanatomical studies of hepatic portal osmo- and sodium-receptive afferent projections within the brain. $\mathbf{J}$ Autonom Nerv Syst 1: 182-202

49. Rolls ET (1978) Neurophysiology of feeding. In: Tins. Elsevier Press, Amsterdam Oxford New York, p 1-3

50. Rolls ET, Burton MJ, Mora F (1976) Hypothalamic neuronal responses associated with the sight of food. Brain Res 111: 53-66

51. Rowland N, Meile MJ, Nicolaidis S (1973) Action inadéquate des apports parentéraux sur l'insulinosécrétion et sur le contrôle du comportement alimentaire chez le rat. C R Acad Sci (Paris) 227: 1783-1786

52. Scott JW, Pfaffmann C (1972) Characteristics of responses of LH neuron stimulation of the olfactory system. Brain Res 48: 251-264

53. Shimazu T, Fukuda A, Ban T (1966) Reciprocical influences of the ventromedial and lateral hypothalamic nuclei on blood glucose level and liver glycogen content. Nature 210: $1178-1179$

54. Steffens $A B$ (1970) Plasma insulin content in relation to blood glucose level and meal pattern in the normal and hypothalamic rat. Physiol Behav 5: 147-151

55. Steffens $A B$ (1976) The influence of the oral cavity on the release of insulin in the rat. Am J Physiol 230: 1411-1415

56. Steffens AB, Mogenson GJ, Stevenson JAF (1972) Blood glucose, insulin and free fatty acids after stimulation of the hypothalamus. Am J Physiol 222: 1446-1452

57. Strubbe JH, Steffens AB (1975) Rapid insulin release after ingestion of a meal in the unanesthetized rat. Am J Physiol 229: 1019-1022

58. van Houten M, Posner BI, Kopriwa BM, Brawer JR (1979) Insulin-binding sites in the rat brain: in vivo localization to the 
circumventricular organs by quantitative radioautography. Endocrinology 105: 666

59. van Itallie TB, Gale SK, Kissileff HR (1980) Control of food intake in the regulation of depot fat: an overview. In: Katzen HM, Mahler RJ (eds) Advances in modern nutrition, vol 2 Wiley Press, New York, p 427-492

60. Vincent JD, Arnaud E, Bioulac B (1972) Activity of osmosensitive single cells in the hypothalamus of the behaving monkey during drinking. Brain Res 44: 371-384

61. Wayner MJ, Barone K (in press) Effects of intragastric water infusions, stomach distension, and vagus nerve stimulation on hypothalamic neuronal activity. Brain Res Bull

62. Woods SC (1972) Conditioned hypoglycemia: effect of vagotomy and pharmacological blockade. Am J Physiol 223: $1424-1427$
63. Woods SC, Lotter EC, McKay LD, Porte D Jr (1979) Chronic intracerebroventricular infusion of insulin reduces food intake and body weight of baboons. Nature 282: 503-505

64. Woods SC, Porte D Jr (1974) Neurol control of the endocrine pancreas. Physiol Rev 54: 596-619

65. York DA, Bray GA (1972) Dependence of hypothalamic obesity on insulin, the pituitary and the adrenal gland. Endocrinology 90: 885-894

Stylianos Nicoloidis

Laboratoire de Neurobiologie des Régulations

C.N.R.S.-Collège de France

11, Place Marcelin Berthelot

F-75231 Paris Cedex 05

France

\section{Discussion after the Presentation by Nicolaidis:}

Berthoud: Have you infused lipolytic agents into the hypothalamus to see if the rats would eat more and gain weight?

Nicolaidis: Yes, we are continuing these studies now. The results are not as dramatic as when we infuse the lipogenic agent insulin, but they are suggestive nevertheless. So far we have used epinephrine and a few cyclic-AMP modifiers. Sometimes these agents work and sometimes they don't. The results are not so reproducible, but we have seen reliable increases of food intake and body weight.

Steffens: Since catecholamines are elevated when eating occurs, could the increase of oxygen consumption you see when animals eat simply be caused by increased epinephrine and nor-epinephrine?

Nicolaidis: That's possible, of course, but elevated catecholamines do not increase oxygen consumption in all tissues; and in fact, it may go down in some tissues. We measure total body oxygen consumption in our experiments.

Porte: Actually, in humans, I would think that whole body oxygen consumption would be increased by epinephrine. It is certainly stimulated in muscle and adipose tissue. What tissues are not stimulated?

Nicolaidis: Brain, the intestines and connective tissue do not increase their oxygen consumption to increased epinephrine.

Van Houten: At the electron microscopic level, we have seen neurons in the basal hypothalamus which appear to have increased levels of phospholipids in membranes associated with the endoplasmic reticulum (J Comp Neurol (1978) 178: 89). Like both yourself and Panksepp, we have wondered whether these cells might be an analogue of the periphery. Unfortunately, we haven't been able to pursue this work for want of a method of quantification.

Nicolaidis: I am encouraged by your findings and hope you find a way to pursue them. Perhaps you could look at animal models which have altered body weights.

Sclafani: Can you be certain that your prolonged infusions are not simply damaging the lateral hypothalamic area since damage there would cause the same results?

Nicolaidis: Yes, we have made extensive examinations of the brains of all of our rats and have found no evidence of damage. Further, the control rats receive the same volume and rate of infusion but yield different results.

Smith: What were the specific changes of lipid content which you observed in the hypothalamus of rats at elevated weights?

Nicolaidis: The main increase was in triglyceride content. We found no change of sphingolipids, thus not agreeing completely with the findings of Dr. van Houten.

Oomura: Because of the controversies concerning the actual sites in the hypothalamus which control insulin secretion. Dr. Niijima and I have recently collaborated on an experiment attempting to clear up some of the controversy. We recorded from the vagal and splanchnic nerves to the pancreas while stimulating the hypothalamus. Electrical stimulation of the ventral part of the LHA caused increased vagal activity and decreased splanchnic activity. Stimulation of the dorsal LHA caused a decrease of vagal activity. Stimulation of the VMH typically caused decreased vagal and increased splanchnic activity, although a few sites increased vagal activity as well. Since there are two distinct areas and responses in the LHA, it is not surprising that controversial results have been reported.

Responsible for the text: Dr. A. G. Cudworth, Department of Diabetes, Medical Unit, King George V Building (5th Floor), St. Bartholomew's Hospital, London ECIA 7BE, England

Responsible for advertisements: L. Siegel, B. Schultz, Kurfürstendamm 237, D-1000 Berlin 15. Springer-Verlag Berlin Heidelberg New York

Printed in Germany by aprinta, Wemding

Copyright @ Springer-Verlag Berlin Heidelberg 1981 